\title{
Evaluation of Neuroprotective Activity of Bauhinia Variegata on Reserpine Induced Catalepsy in Rats
}

\author{
Authors \\ Vishakha Trivedi*, Mrs Rachana D. Sarawade**, Siddhi Mehta, Ayyub Shaikh \\ *Department of Pharmacology, Dr. L.H.Hiranandani College of Pharmacy \\ ULHASNAGAR, MUMBAI. \\ **Assistant Professor and HOD Pharmacology \\ Dr.L.H.Hiranandani College of Pharmacy, Ulhasnagar, Mumbai
}

Email:vsh_tri@yahoo.co.in

\begin{abstract}
An acetone soluble leaf extract from Bauhinia variegata was investigated for its neuroprotective effects in the reserpine induced catalepsy rat model of the disease by measuring behavioural and biochemical parameters in the model. In rat model catalepsy was induced by administration of reserpine $(2.5 \mathrm{mg} / \mathrm{kg}, \mathrm{p.o})$ in wistar rats of either sex. A significant reduction in the catalepsy was observed in the drug treated groups when compared to the disease induced group. The biochemical parameters were Lipid peroxidation, Glutathione(GSH), Glutathione peroxidase (GSH-Px) and superoxide dismutase (SOD) were assessed in brain. Administration of reserpine resulted in increased lipid peroxidation and decreased levels of antioxidant enzymes i.e GSH,GSH-Px and SOD. The study showed that the plant extract significantly decreased lipid peroxidation levels and increased antioxidant enzyme levels.

KEYWORDS: Bauhinia variegata, neuroprotective, antioxidant, antioxidant enzymes
\end{abstract}

\section{INTRODUCTION}

The term neurodegeneration is derieved from the two words - "neuro," referring to nerve cells and "degeneration," referring to progressive damage. Thus neurodegeneration corresponds to any pathological condition primarily affecting neurons. In practice, neurodegenerative diseases represent a large group of neurological disorders with heterogeneous clinical and pathological expressions affecting specific subsets of neurons ${ }^{[1]}$. The process of neurodegeneration unfolds at the cellular level in which, oxidative stress and excitotoxicity, act persistently to inflict the majority of cell damage and death. Although many factors can play a direct role in the initiation of neurodegeneration, the two forces which interact at the cellular level are free radicals formed by the reactive oxygen species and reactive nitrogen species, and secondly, excitotoxins, such as glutamate. Excitotoxins are neurotransmitters which can cause cell death when their actions are prolonged ${ }^{[2]}$.

Parkinson's disease (PD) is the most prevalent neurodegenerative disorder caused by a progressive loss of dopaminergic (DA-ergic) neurons in substantia nigra pars compacta $(\mathrm{SNpc})$ 1 and the development of fibrillar cytoplasmic inclusions containing $\alpha$-synuclein and ubiquitin. It is mainly characterized by four cardinal features which are bradykinesia, resting tremor, rigidity 
(stiffness of limbs) and postural reflex impairment (gait or balance problem). PD was first described by James Parkinson in 1817 as paralysis agitans, or the "shaking palsy". Parkinson's Disease is a rare occurrence, affecting approximately 1 in 300 people. As per current statistics, about 7-10 million people in the world are living with Parkinson's disease ${ }^{[3]}$. Several factors are responsible for the neurodegeneration like mitochondrial complex-1 inhibition, interaction between environmental and genetic factors, environmental toxins like metals, proteosomal dysfunction and microglial activation ${ }^{[4]}$

Free radicals generated due to these defects could be responsible for the oxidative damage in dopamine metabolism, resulting in generation of reactive oxygen species. The reduced levels of endogenous antioxidant molecules such as glutathione (GSH) and superoxide dismutase (SOD), increased levels of nitric oxide (NO) and lipid peroxidation product malondialdehyde (MDA) in the brain could lead to neuronal death. These conditions lead to the requirement of using antioxidants as a treatment in PD in addition to other protective agents.

Bauhinia variegata Linn., commonly known as 'Kachnar', is a small sized deciduous tree with dark brown and smooth bark, up to $8 \mathrm{~m}$ tall; propagated by seed. The roots and bark are astringent, acrid, cooling, constipating, depurative, anthelmintic, vulnerary, anti-inflammatory and styptic. Further these are also useful in curing diarrhoea, dysentery, skin diseases, leprosy, intestinal worms, tumours, inflammations, scrofula, proctoplosis, haemorrhoids, haemoptysis, cough, menorrhagia and diabetes. Root decoction is used in dyspepsia and flatulence and act as an antidote to snake poison ${ }^{[5]}$.

\section{MATERIALS AND METHODS}

\subsection{Plant material}

The leaves of Bauhinia variegata were collected from Lila Nursery, Santacruz, Mumbai. Bauhinia variegata leaves were authenticated by $\mathrm{Dr}$ H.M.Pandit, Khalsa College, Matunga Mumbai.
Bauhinia variegata is also commonly known as kachnara.

\subsection{Extraction of Bauhinia variegata}

Air dried leaves of Bauhinia variegata were powdered. The powdered leaves were macerated with Acetone and water in a closed flask. This mixture was shaken frequently during the first 6 hours. Thereafter it was allowed to stand for 18 hours. The solution was then filtered and the filterate obtained was air dried to obtain the required extract. Test suspension was prepared by suspending $15 \mathrm{mg}$ of acetone soluble extract in 15 $\mathrm{ml}$ of distilled water in the presence of $0.5 \%$ Sodium Carboxymethyl Cellulose.

\subsection{Experimental animals}

Wistar rats weighing 180-220 gm body weight of either sex, were procured from Bharat Serum and Vaccines Thane. The animals were maintained in a well-ventilated room with a 12-hour light/dark cycle in standard polypropylene cages under controlled temperature $\left(26 \pm 1^{\circ} \mathrm{C}\right)$ and humidity $(30 \%-40 \%)$. They were fed with a standard pellet diet. Experimental protocols were approved by Institutional Animal Ethics Committee (IAEC) of C.P.C.S.E.A.

\subsection{Acute toxicity studies of Bauhinia variegata}

Rats selected by a random sampling technique were used in the study. Acute oral toxicity was performed as per Organization for Economic Cooperation and Development (OECD)-423 guidelines. Three male Wistar rats weighing between 180-220 g were used for each dose. The dose level of $2000 \mathrm{mg} / \mathrm{kg} /$ body weight was selected. The drug was administered orally to rats, which were fasted overnight with water ad libitum before the administration of the drug. The body weight of the rat was noted before and after treatment. The animals were observed for toxic symptoms, such behavioral changes, locomotion, convulsions, and mortality for 14 days. 


\subsection{Reserpine induced catalepsy ${ }^{[6]}$}

Rats were treated with reserpine for 5 consecutive days to generate acute DA depletion. Reserpine was dissolved in few drops of $1 \%$ glacial acetic acid and the volume was made upto the required amount using water for injection.This solution was injected i.p. at a concentration of $2.5 \mathrm{mg} / \mathrm{kg}$.

\subsubsection{Behavioral Parameters}

2.6.1.1 Bradykinesia : In the impaired ability to initiate movements, the mouse was held by the tail so that he is standing by his forelimbs and moving on his own. The number of steps taken with both forelimbs was recorded for $30 \mathrm{~s}$. The existence of bradykinesia (movements in parkinsonian rats are slower than observed in healthy controls) was measured by placing the animal's forepaws on a horizontal wooden bar ( $0.7 \mathrm{~cm}$ in diameter), $4 \mathrm{~cm}$ above the tabletop. The time until the mouse removed both forepaws from the bar was recorded, with a maximum cut off time of 3 min.

2.6.1.2 Palpebral ptosis: The anomalous sagging of the upper lid, caused by partial or total decrement in levator muscle function was scored in the following way:

4 , eyes completely closed;

2 , half-open eyes; and

0 , wide-open eyes; with

1 and 3 indicating intermediate values.

\subsubsection{Biochemical parameters:}

Evaluation of Antioxidant Enzymes as follows:

On $21^{\text {st }}$ day after behavioral assessments, animals were sacrificed by cervical dislocation and brains were removed. The cerebellum was discarded and the remaining brain tissue was weighed and preserved at $-20^{\circ} \mathrm{C}$ in deep freezer till further analysis. The known weight of brain tissue was homogenized for the estimation of antioxidant enzymes as follows.

\subsubsection{Lipid Peroxidation (LPO)}

Lipid peroxidation was estimated colorimetrically in brain tissue by quantifying TBARS according to the method of Niehaus and Samuelson. In brief; for the estimation of TBARS the supernatant of the tissue homogenate was treated with tertiary butanol-trichloroaceticacid-hydrochloricacid,

(TBA-TCA-HCl) reagent and mixed thoroughly. The mixture was kept in boiling water bath for 15 minutes. After cooling, the tubes were centrifuged for 10 minutes and the supernatant taken for measurement. The developed color was read at $535 \mathrm{~nm}$ using a UV spectrophotometer against a reagent blank and expressed as $\mathrm{mM}$ per $100 \mathrm{~g}$ tissue.

\subsubsection{Glutathione (GSH)}

The amount of GSH in mice brain was measured according to the method of Sedlak and Lindsay (1968). Briefly, brain tissue was deproteinized with an equal volume of $10 \%$ trichloroacetic acid and was allowed to stand at $40 \mathrm{C}$ for $2 \mathrm{~h}$. The contents were centrifuged for $15 \mathrm{~min}$. The supernatant was added to Tris buffer $(\mathrm{pH}$ 8.9) containing ethylene diamine tetraacetic acid (EDTA) (pH 8.9) followed by the addition of 0.01 M 5,50-dithiobis(2-nitrobenzoic acid) (DTNB). Finally, the mixture was diluted with distilled water, to make the total mixture to $3 \mathrm{ml}$ and absorbance was read in a spectrophotometer at $412 \mathrm{~nm}$ and results are expressed as $\lg \mathrm{GSH} / \mathrm{g}$ tissue

\subsubsection{Glutathione Peroxidase (GSH-Px)}

Rotruck and his coworkers measured the activity of glutathione peroxidase. The reaction mixture contained $0.4 \mathrm{M}$ tris $\mathrm{HCl}$ buffer $(\mathrm{pH}=7.0), 0.2 \mathrm{ml}$ standard glutathione (GSH) and $0.2 \mathrm{mM}$ $\mathrm{H} 2 \mathrm{O} 2$. The contents were incubated at $37 \square \mathrm{C}$ for 10 minutes. The supernatant was assayed for glutathione content by using Ellman's reaagent. GPx activity was expressed as mg of GSH utilized /minute/mg tissue.

\subsubsection{Super Oxide Scavenging Activity (SOD)}

The assay of SOD was based on the ability of SOD to inhibit spontaneous oxidation of adrenaline to adrenochrome. To the supernatant, carbonate buffer and EDTA were added. The 


\section{JMSCR Vol||3||Issue||9||Page 7421-7428||September}

reaction was initiated by addition of $0.5 \mathrm{~mL}$ of epinephrine and the auto-oxidation of adrenaline to adrenochrome at $\mathrm{pH} 10.2$ was measured by following changes in optical density at $480 \mathrm{~nm}$. The changes in optical density every minute were measured at $480 \mathrm{~nm}$ against a reagent blank. The results are expressed as units of SOD activity . One unit of SOD activity induced approximately $50 \%$ inhibition of adrenaline. The results were expressed as nmol SOD U per mg wet tissue.

\section{STATICAL ANALYSIS}

All values were reported as mean + S.E.M. Results were significantly analyzed using one way ANOVA by Dunnett test $\mathrm{p}<0.05$ was considered to be significant.

Acute toxicity studies: Acute toxicity studies was carried out to evaluate toxicity and to determine the minimum lethal dose of the drug extract .ASE did not show any toxic or deleterious effects up to $2000 \mathrm{mg} / \mathrm{kg}$ oral dose. As the rats were administered up to maximal possible dose, the LD50 value of ASE could not be determined.

\subsection{Reserpine induced Behavioural changes in rats:}

\subsubsection{Palpebral ptosis:}

Table 1: Palpebral ptosis

\begin{tabular}{|l|l|l|l|l|}
\hline $\begin{array}{l}\text { Time } \\
(\mathrm{mins})\end{array}$ & Vehicle Control & $\begin{array}{l}\text { Reserpine } \\
(\text { Disease Control })\end{array}$ & ASE $(800 \mathrm{mg} / \mathrm{kg})$ & $\begin{array}{l}\text { Standard Selegiline } \\
(15 \mathrm{mg} / \mathrm{kg})\end{array}$ \\
\hline 30 & $0.250 \pm 0.112$ & $1.750 \pm 0.250^{*}$ & $0.417 \pm 0.201^{* *}$ & $0.333 \pm 0.247^{* *}$ \\
\hline 60 & $0.583 \pm 0.201$ & $1.833 \pm 0.279^{*}$ & $0.333 \pm 0.211^{* *}$ & $0.333 \pm 0.105^{* *}$ \\
\hline 90 & $1.250 \pm 0.171$ & $3.00 \pm 0.289^{*}$ & $1.250 \pm 0.171^{* *}$ & $1.083 \pm 0.201^{* *}$ \\
\hline 120 & $0.917 \pm 0.239$ & $2.917 \pm 0.239^{*}$ & $1.500 \pm 0.129^{* *}$ & $1.417 \pm 0.154^{* *}$ \\
\hline 150 & $0.667 \pm 0.167$ & $3.00 \pm 0.289^{*}$ & $1.917 \pm 0.154^{* *}$ & $1.750 \pm 0.171^{* *}$ \\
\hline 180 & $0.833 \pm 0.167$ & $2.750 \pm 0.423^{*}$ & $2.083 \pm 0.154^{* *}$ & $2.083 \pm 0.201^{* *}$ \\
\hline
\end{tabular}

Values are expressed as Mean \pm SEM determined by One-way ANOVA followed by Dunnett's multiple comparison tests. $*$ : $\mathrm{p}<0.05$ when compared with Vehicle control group, **: $\mathrm{p}<0.05$ when compared with Disease control group.

\section{Palpebral Ptosis}

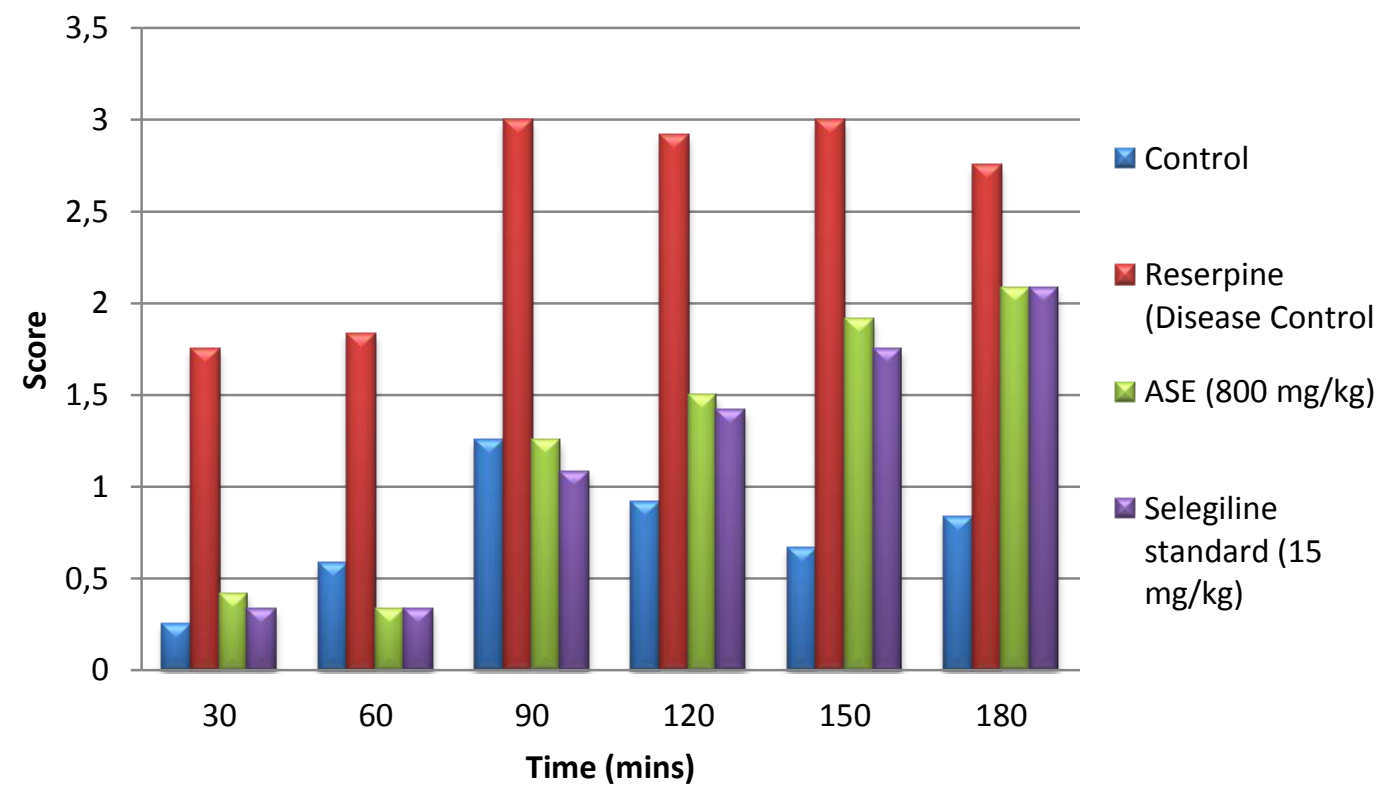

Graph 1: Muscular rigidity by Palpebral ptosis 
There was a significant decrease in Palpebral ptosis in (Standard) Selegiline $(15 \mathrm{mg} / \mathrm{kg}$ ) treatment group and (Test) ASE $800 \mathrm{mg} / \mathrm{kg}$ treatment group as compared to Reserpine $(2.5 \mathrm{mg} / \mathrm{kg})$ treatment group. Also, there was a significant increase in Palpebral ptosis in Reserpine treatment group as compared to Control group.

\section{2: Locomotion by Actophotometer}

Table 2: Locomotion by Actophotometer

\begin{tabular}{|l|l|l|l|l|}
\hline Day & Vehicle Control & $\begin{array}{l}\text { Reserpine } \\
(\text { Disease Control) }\end{array}$ & ASE $(800 \mathrm{mg} / \mathrm{kg})$ & $\begin{array}{l}\text { Standard Selegiline } \\
(15 \mathrm{mg} / \mathrm{kg})\end{array}$ \\
\hline 1 & $319.8 \pm 5.913$ & $134.8 \pm 3.321^{*}$ & $287.7 \pm 0.882^{* *}$ & $299.1 \pm 1.542^{* *}$ \\
\hline 2 & $321.5 \pm 5.909$ & $133.3 \pm 2.996^{*}$ & $289.3 \pm 0.715^{* *}$ & $301.2 \pm 1.078^{* *}$ \\
\hline 3 & $316.8 \pm 6.715$ & $127.5 \pm 1.432^{*}$ & $288.5 \pm 0.764^{* *}$ & $301.3 \pm 1.994 * *$ \\
\hline 4 & $317.0 \pm 6.143$ & $124.8 \pm 1.493^{*}$ & $291.3 \pm 1.256^{* *}$ & $303.7 \pm 1.229 * *$ \\
\hline 5 & $322.2 \pm 3.544$ & $122.0 \pm 1.826^{*}$ & $296.8 \pm 1.138^{* *}$ & $306.7 \pm 1.333^{* *}$ \\
\hline
\end{tabular}

Values are expressed as Mean \pm SEM for 6 rats in each group. Significance was determined by One-way ANOVA followed by Dunnett's multiple comparison tests. *: $\mathrm{p}<0.05$ when compared with Vehicle control group, **: $\mathrm{p}<0.05$ when compared with Disease control group.

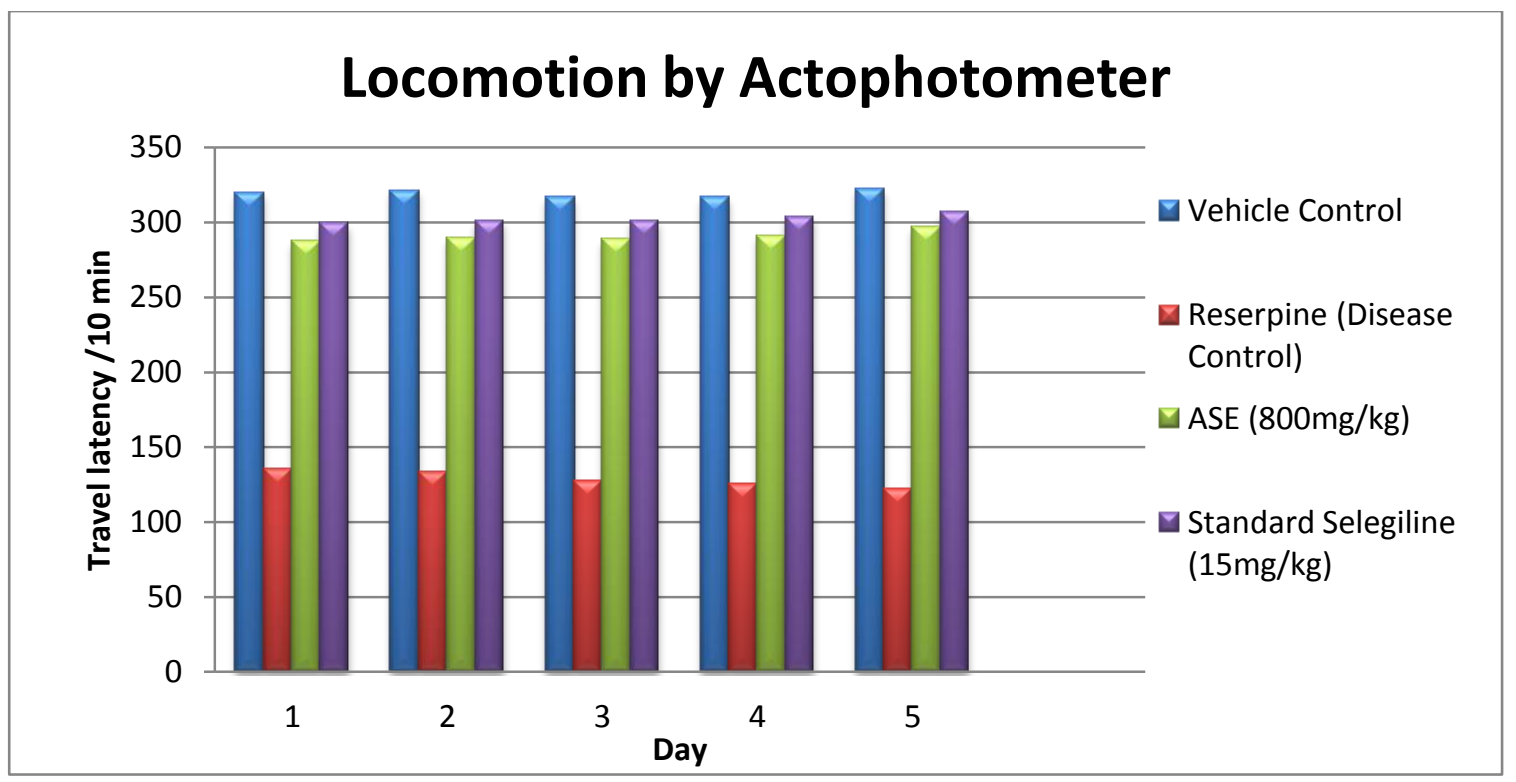

There was a significant increase in locomotion in (Standard) Selegiline $(15 \mathrm{mg} / \mathrm{kg}$ ) treatment group and (Test) ASE $800 \mathrm{mg} / \mathrm{kg}$ treatment group as compared to Reserpine $(2.5 \mathrm{mg} / \mathrm{kg})$ treatment group. Also, There was a significant decrease in locomotion in Reserpine treatment group as compared to Control group. This shows that locomotion in Test drug ASE treated group is increased due to its anti-Parkinsonian activity.

\subsection{Bradykinesia}

Table 3 :Bradykinesia

\begin{tabular}{|l|l|l|l|l|}
\hline Day & Vehicle Control & $\begin{array}{l}\text { Reserpine } \\
(\text { Disease Control) }\end{array}$ & ASE $(800 \mathrm{mg} / \mathrm{kg})$ & $\begin{array}{l}\text { Standard Selegiline } \\
(15 \mathrm{mg} / \mathrm{kg})\end{array}$ \\
\hline 1 & $121.1 \pm 1.272$ & $113.5 \pm 1.694^{*}$ & $119.7 \pm 0.8476^{* *}$ & $122.6 \pm 1.749 * *$ \\
\hline 2 & $122.7 \pm 2.923$ & $114.1 \pm 0.9333^{*}$ & $120.9 \pm 0.534^{* *}$ & $123.2 \pm 0.6618^{* *}$ \\
\hline 3 & $121.5 \pm 1.950$ & $114.1 \pm 0.8093^{*}$ & $123.0 \pm 1.855^{* *}$ & $126.5 \pm 0.5024 * *$ \\
\hline 4 & $120.8 \pm 2.702$ & $114.4 \pm 1.209^{*}$ & $122.3 \pm 0.6784 * *$ & $126.6 \pm 1.382^{* *}$ \\
\hline 5 & $122.7 \pm 2.180$ & $107.1 \pm 1.616^{*}$ & $121.5 \pm 2.258^{* *}$ & $124.5 \pm 1.371 * *$ \\
\hline
\end{tabular}




\section{JMSCR Vol||3||Issue||9||Page 7421-7428||September}

Values are expressed as Mean \pm SEM for 6 rats in each group. Significance was determined by One-way ANOVA followed by Dunnett's multiple comparison tests. $*$ : $\mathrm{p}<0.05$ when compared with Vehicle control group, **: $\mathrm{p}<0.05$ when compared with Disease control group

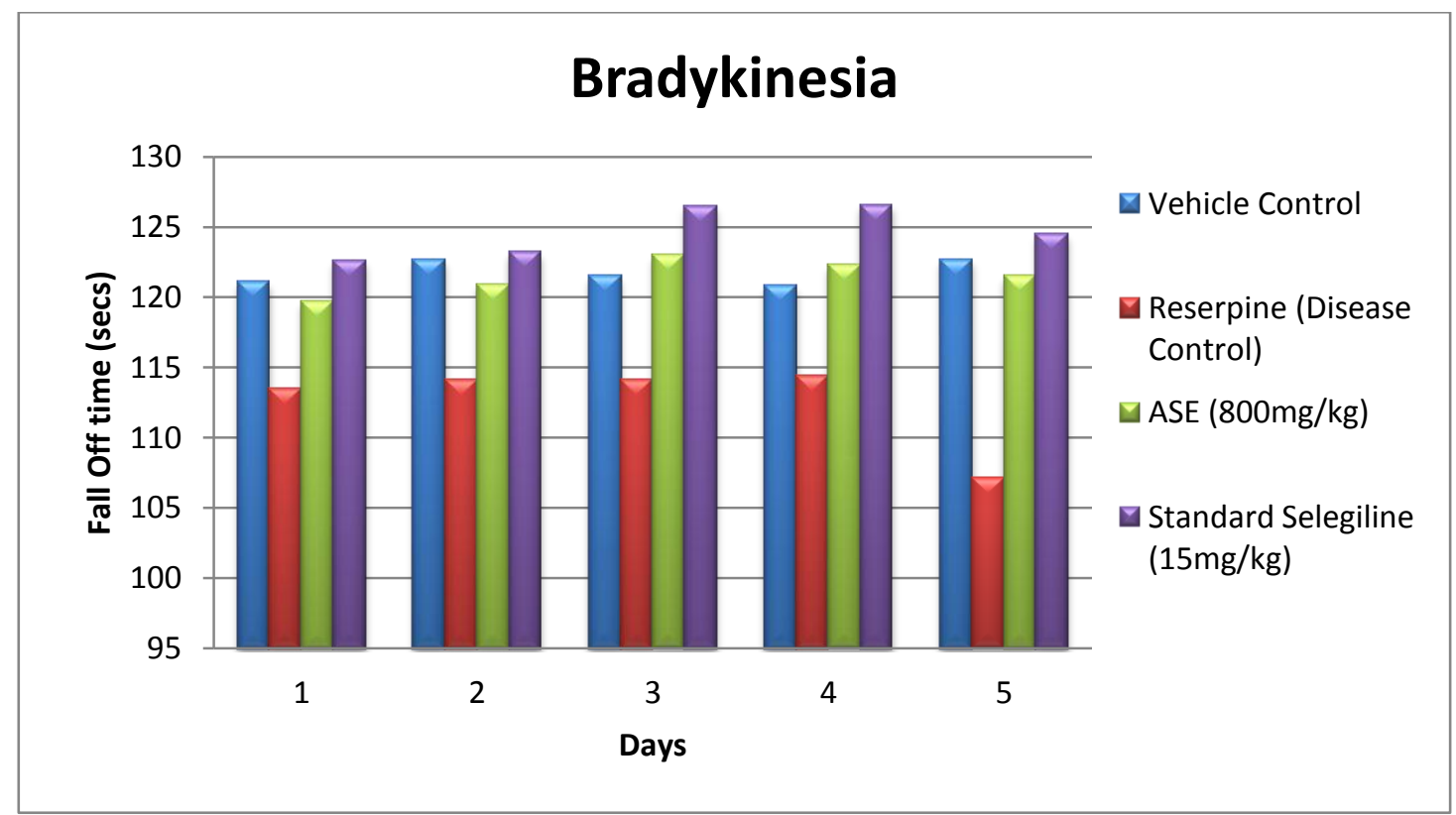

There was a significant increase in the time taken by the animal to remove its paw from the bar in (Standard) Selegiline $(15 \mathrm{mg} / \mathrm{kg})$ treatment group and (Test) ASE $800 \mathrm{mg} / \mathrm{kg}$ treatment group as compared to Reserpine $(2.5 \mathrm{mg} / \mathrm{kg})$ treatment group. Also, There was a significant decrease in time taken in Reserpine treatment group as compared to Control group. This shows that ASE treated group withstands the hold and has a grip on bar for longer duration than other groups, thus it indicates Test drug ASE has ability to treat muscle weakness or rigidity like Parkinson symptoms.

\subsection{Biochemical parameters (Antioxidant Enzymes)}

Table 4 : Biochemical parameters

\begin{tabular}{|c|c|c|c|c|}
\hline Groups & $\begin{array}{l}\text { Lipid Peroxidation } \\
\text { (LPO) } \\
(\mathrm{mM} / \mathrm{mg} \text { tissue) }\end{array}$ & $\begin{array}{l}\text { Glutathione } \\
\text { (GSH) } \\
\text { (uM/mg tissue) }\end{array}$ & $\begin{array}{l}\text { Glutathione } \\
\text { peroxidise GSH-Px } \\
(\mathrm{nmol} / \mathrm{min} / \mathrm{ml})\end{array}$ & $\begin{array}{l}\text { Superoxide } \\
\text { dismutase (SOD) } \\
\text { (U/g tissue) }\end{array}$ \\
\hline Vehicle Control & $2.189 \pm 0.0379$ & $0.0840 \pm 0.0015$ & $8.203 \pm 0.0701$ & $0.6482 \pm 0.0124$ \\
\hline $\begin{array}{l}\text { Reserpine (Disease } \\
\text { Control) }\end{array}$ & $7.792 \pm 0.0861 *$ & $\begin{array}{ll}0.03317 & \pm \\
0.0016^{*} & \end{array}$ & $3.212 \pm 0.1584^{*}$ & $0.2352 \pm 0.017 *$ \\
\hline ASE (800mg/kg) & $2.777 \pm 0.0992 * *$ & $\begin{array}{ll}0.06633 & \pm \\
0.0018 * * & \end{array}$ & $7.245 \pm 0.1413 * *$ & $\begin{array}{l}0.5915 \\
0.0077 * *\end{array}$ \\
\hline $\begin{array}{l}\text { Standard Selegiline } \\
(15 \mathrm{mg} / \mathrm{kg})\end{array}$ & $2.614 \pm 0.0478 * *$ & $\begin{array}{l}0.07717 \pm 0.001 \\
* *\end{array}$ & $7.922 \pm 0.097 * *$ & $\begin{array}{l}0.6055 \\
0.0048 * *\end{array}$ \\
\hline
\end{tabular}


Values are expressed as Mean \pm SEM for 6 ratsin each group. Significance was determined by One-way ANOVA followed by Dunnett's multiple comparison tests. $\quad *$ : $<<0.05$ when compared with Vehicle control group, **: $\mathrm{p}<0.05$ when compared with Disease control group.

GSH-Px and SOD were found to be significantly increased in Standard treatment and ASE $100 \mathrm{mg} / \mathrm{kg}$ and ASE $500 \mathrm{mg} / \mathrm{kg}$ treatment group as compared to Reserpine treatment group. These enzymes were found to be significantly decreased in Reserpine group as compared to Control group. Also the levels of the lipid peroxidation (LPO) and GSH were found to significantly decrease in Standard and ASE treated groups when compared to the disease controlled group. This shows that Test drug has increased antioxidant enzyme levels in Reserpine treated rats. Thus ASE shows anti parkinsonian effect by possessing antioxidant activity.

\section{DISCUSSION}

The administration of RES (2.5 $\mathrm{mg} / \mathrm{kg})$ intraperitoneally for five consecutive days in rats, irreversibly blocks the uptake and storage of norepinephrine and DA into synaptic vesicles by inhibiting the vesicular monoamine transporter (VMAT).This blockage interferes with the storage of monoamines into the vesicle, which results in the depletion of catecholamines in nerve terminals. The accumulation of neurotransmitters in the synaptic terminal leads to an increase in the metabolism of these substances by monoaminoxidase, generating free radicals and cellular damage by increased oxidative stress. The changes in neurochemical balance generated by RES are associated with behavioral deficits predominantly in motor activity ${ }^{[10]}$.

In the present study in Reserpine treatment group, showed decreased locomotion and muscular rigidity. This difference in the behavioural changes was due to the blockade of the VMAT receptors by reserpine. ASE $(800 \mathrm{mg} / \mathrm{kg})$ treated group reduced the muscular rigidity and increased locomotion in a dose dependent manner in Reserpine treated groups. Rats were treated intraperitoneally with reserpine for five consecutive days at a concentration of $2.5 \mathrm{mg} / \mathrm{kg}$ to then apply several motor tests. The doses administrated in the present study were effective in inducing a significant reduction in monoamine levels in the CNS of rats. The appearance of bradykinesia, tremor and muscular rigidity induced by RES administration provides a useful animal model of Parkinsonism. The extent of bradykinesia in animals treated with ASE were significantly better than those of the animals treated with the disease inducing agent i.e reserpine. The levels of the antioxidant enzyme (GSH-Px and SOD) were greatly reduced in case to the disease controlled animals. Also the level of lipid peroxidation and GSH was increased to a large extent. The animals treated with the ASE extract showed significant increase in the antioxidant enzymes and a further decrease in the Lipid peroxidation and GSH levels was observed.

\section{CONCLUSION}

The present study thus, provides sufficient evidence that ASE, an antioxidant of natural origin medicinal plant can be used as an effective anti-PD drug due to its neuroprotective activity. ASE can be employed as an effective anti-PD drug as it shows improvement in dopamine neurotransmission and also prevents neurodegeneration. Further studies are required on molecular mechanism and molecular pathways for the potential use of ASE as a neuroprotective in Parkinson's disease.

\section{ACKNOWLEDGEMENT}

I would like to thank my guide Mrs Rachana D. Sarawade, for the guidance and support I received. Also special acknowledgement to my principal, Dr.Paarag Gide and my college Dr.L.H. Hiranandani College of Pharmacy for providing suitable environment for research work and facilities. 


\section{REFRENCES}

1. Przedborski S, Vila M, Jackson-Lewis V. Neurodegeneration: What is it and where are we? The Journal of Clinical Investigation ,January 2003, Volume 111, Number 1.

2. Marshall R J. "The Overlooked Role of Chronic Infection in Neurodegeneration and Its Reversal Using Nutraceutical Agents".

3. Rupavate S.(2014) Available at http://www.thehealthsite.com/diseasesconditions/world-parkinsons-day-2014-10facts-about-parkinsons-disease/. Accessed on: 10 January 2015.

4. Wooten GF. Neurochemistry and neuropharmacology of Parkinson's disease. In: Watts RL, Koller, editors. Movement disorders; Neurologic principles and practice. New York: McGraw Hill; 1997. p. 153-160.

5. Sahu $G$ and Gupta PK. A review on Bauhinia variegata linn. International research Journal of pharmacy 2012;3(1):48-51.

6. Calderon J.L and Bolanos R, Behavioral Analysis of the Reserpine Induced Motor Changes in a Parkinsonian Mouse Model. Revista Neuropsicología, Neuropsiquiatría y Neurociencias, October 2011, Vol.11, №2, pp. 49-61.

7. Niehaus WG, Samuelson B. Formation of malondialdehyde from phospholipid arachidonate during microsomal lipid peroxidation. Eur J Biochem. 1968;6:126130.

8. Rotruck JTAL, Pope HE and Ganther AB Swanson Biochemical role as acomponent of glutathione peroxidase. J science., 1973; 179: 588-590.

9. Bowling AC, Schulz JB, Brown RH, Beal MF. Superoxide dismutase activity, oxidative damage, and mitochondrial energy metabolism in familial and sporadic amyotrophic lateral sclerosis. J Neurochem 1993;61:2322-5.

10. Bafna P; Effect of aqueous extract of cynodondactylon on reserpine induced catalepsy; International Journal of Pharmacy and Pharmaceutical Sciences Vol 3, Issue 4, 2011. 